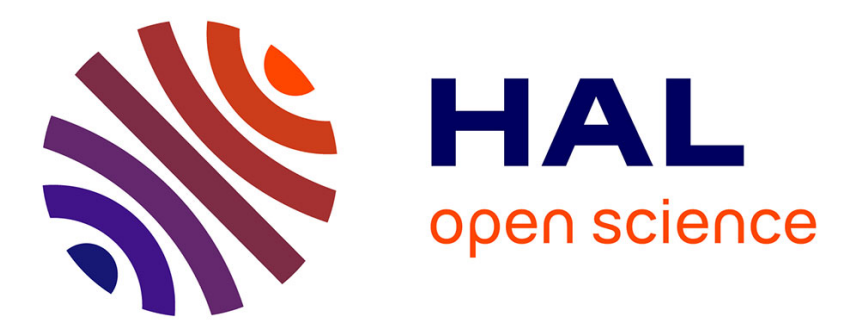

\title{
A joined finite element based method to simulate 3D crack network initiation and propagation in mechanical and thermal fatigue
}

\author{
Jonathan Barés, Lionel Gelebart, Jérémie Rupil, Ludovic Vincent
}

\section{To cite this version:}

Jonathan Barés, Lionel Gelebart, Jérémie Rupil, Ludovic Vincent. A joined finite element based method to simulate 3D crack network initiation and propagation in mechanical and thermal fatigue. International Journal of Fatigue, 2012, 44, pp.279-291. 10.1016/j.ijfatigue.2012.04.005 hal01969608

\section{HAL Id: hal-01969608 \\ https://hal.science/hal-01969608}

Submitted on 7 Jan 2019

HAL is a multi-disciplinary open access archive for the deposit and dissemination of scientific research documents, whether they are published or not. The documents may come from teaching and research institutions in France or abroad, or from public or private research centers.
L'archive ouverte pluridisciplinaire HAL, est destinée au dépôt et à la diffusion de documents scientifiques de niveau recherche, publiés ou non, émanant des établissements d'enseignement et de recherche français ou étrangers, des laboratoires publics ou privés. 


\title{
A joined finite element based method to simulate 3D crack network initiation and propagation in mechanical and thermal fatigue
}

\author{
Jonathan Barés, Lionel Gélébart*, Jérémie Rupil, Ludovic Vincent \\ CEA, DEN, DMN, SRMA, 91191 Gif-sur-Yvette cedex, France
}

\section{A R T I C L E I N F O}

\section{Article history:}

Received 8 November 2011

Received in revised form 14 March 2012

Accepted 2 April 2012

Available online 10 April 2012

\section{Keywords:}

Fatigue crack network

Numerical modeling

Thermal fatigue

Mechanical fatigue

Finite element simulations

\begin{abstract}
A B S T R A C T
A new finite element method is proposed to model the evolution of cracks in a 3D lattice under mechanical and thermal fatigue loading. This step-by-step method, based on the separation of initiation and propagation phenomenon, is tuned by fitted entrance parameters which command fatigue laws. It is founded on linear elasticity assumptions, and the crack's evolution is taken into account by a so-called element deletion method. After the algorithm of the model is presented, two examples of mechanical and thermal fatigue are considered. The evolutions of different crack network characteristic parameters as a function of the number of cycles is proposed and match, at least qualitatively, the general trends observed experimentally.
\end{abstract}

\section{Introduction}

Thermal fatigue is an important issue when designing strategic parts of nuclear PWR (pressurized water reactors). Indeed, several components undergo cyclic thermal loadings which can induce the development of crack networks, even if the temperature fluctuation is relatively small [1]. For instance, this kind of fracture networks may appear on pipes of the primary circuit near cold water injection sites. This can give way to critical leaks when a crack within the network propagates into the pipe wall. Such an incident stopped the Civaux (France) PWR in 1998, just after a leak was detected downstream. The culprit was a T-square shaped pipe, where hot and cold fluids of the cooling system were mixed [2]. This event invoked a lot of research to better understand thermal fatigue in order to ensure the integrity of nuclear power plant components.

Thermal fatigue in pipes is mainly characterized by two specificities. First, the magnitude of stress amplitude caused by the temperature fluctuations decreases rapidly in the depth what generally leads to crack arrest at a certain depth [1]. The second is the biaxial stress state brought about by thermal loading causing complex mechanical interactions between network cracks and hence produces intricate local stress field $[3,4]$. Thus, to understand the initiation and propagation of the crack networks under thermal fatigue loading, several experimental set-ups have been developed

\footnotetext{
* Corresponding author.

E-mail addresses: jonathan.bares@cea.fr (J. Barés), lionel.gelebart@cea.fr (L. Gélébart), jeremie.rupil@cea.fr (J. Rupil), ludovic.vincent@cea.fr (L. Vincent).
}

in research laboratories and a significant amount of experimental data is now at hand [5-9]. These experiments are very time consuming and physical parameters are not always well documented, considered, and/or controlled. Hence, the development of crack network is also under investigation from full-field numerical simulations provided a random set of crack locations and sizes is chosen for each simulation [3,4,10-13]. The technique's advantage is the explicit accountability of the thermal stress gradient versus material depth and how the shielding and coalescence effects occur between the network cracks. The finite element (FE) model developed in this paper, based on the element deletion method [14], gathers the specific advantages of the different quoted papers including: distinction between initiation and propagation laws, stress field evolution as a function of the crack geometry and 3D growing of the cracks. It must be noticed that numerous methods, for example based on the partition of unity concept, have been setup to track three dimensional continuous cracks separating initiation and propagation of the phenomenon. A good review of such methods is given in [14]. These methods give accurate results for mechanical loadings but are computationally heavier than the one presented here. Nevertheless, the novelty of this paper lies more in the application to fatigue (or thermal fatigue) of crack network evolution and in the calibration of the model on experimental results rather than in the development of such recent methods.

A disadvantage of full-field methods is that a high number of simulations are required to obtain statistically confident estimates concerning average values, i.e. crack density. Probabilistic modeling approaches $[15,16]$ are then proposed to directly derive statistical characteristics of the crack networks depending on the 


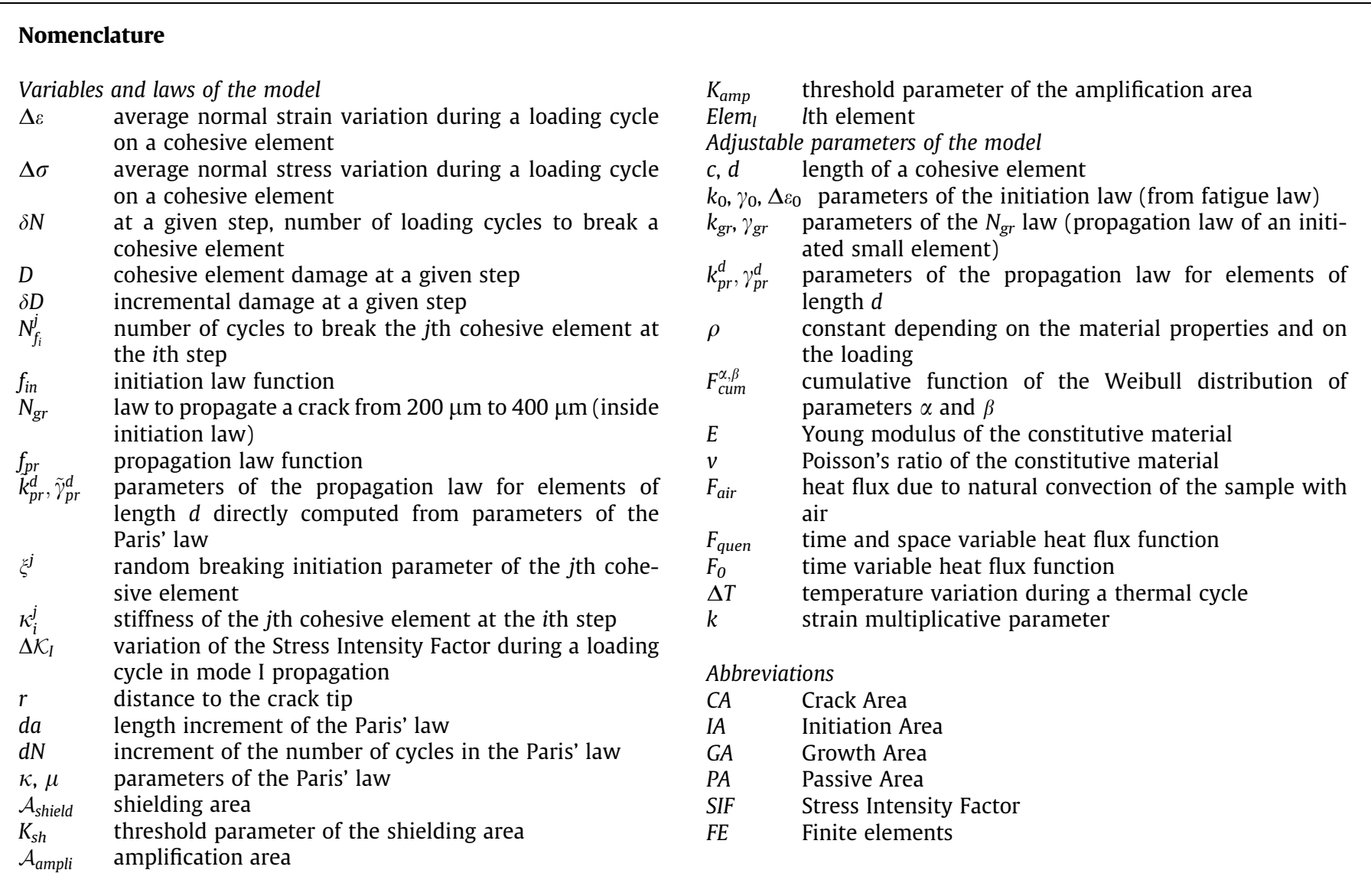

thermal loading conditions and the number of cycles. However, the probabilistic description of crack interactions needs to be verified by the full-field simulations.

In the present paper, the FE model which is an extension of element deletion method is proposed to describe crack network developments. The next section presents the algorithm developed to model mechanical fatigue from linear finite element computations with cohesive elements. Next, the laws used in the model to simulate crack initiation and propagation are introduced. Initiation and propagation parameters are independently fitted on experimental results of uniaxial mechanical fatigue tests. Complete simulations (involving both initiation and propagation) are then performed and compared with experimental tests to check numerically and quantitatively the model's accuracy. Finally, this model is adapted to thermal fatigue using the load induced by a time varying temperature field. Thermal fatigue simulations are carried out and qualitatively analyzed in terms of crack length and density at the free surface and in depth.

\section{Numerical fatigue model}

The main idea of the model is to use a regular 3D finite element mesh with cohesive elements linking volume elements. Hence, crack evolution (initiation and propagation) can be simulated by a sharp stiffness reduction of the failed cohesive elements. Such a method allows accounting for the stress redistributions associated with the evolution of the crack network after each element failure. If crack propagation is assumed to be purely deterministic, crack initiation is related to the definition of a stochastic failure parameter drawn for each element. Finally, consistently with fatigue experimental results of polycrystalline alloys, initiation is restricted to the cohesive elements emerging at the free surface of the sample while propagation is restricted to the ones located in the neighborhood of the crack tips. Hence, as the fatigue behavior of an element depends on its position with respect to the crack tips, this approach can be regarded as non-local.

\subsection{Presentation of the model}

\subsubsection{Model assumptions}

The first and main assumption of the model is that material plasticity is negligible: the material behavior is considered as purely linear elastic. Hence, only normal stresses to the cohesive elements are taken into account. This means that one just considers the first mode for crack growth and the normal load for crack initiation which is a rough estimation particularly in multiaxial stress conditions (this will be discussed later in the paper). For the sake of simplicity, the amplitude of the normal stress appearing on cohesive elements when the material is submitted to a macroscopic cyclic loading, $\sum_{m} \pm \Delta \sum$, is evaluated imposing only a monotonous loading equal to $+\Delta \sum$. As a consequence, the effect of the $R$-ratio (minimum stress over maximum) is neglected in the initiation and propagation laws. More specifically, crack closure is not considered even though it might influence the computation of local stress and strain amplitudes. Moreover, one only takes into account the average value of this normal stress $\Delta \sigma$ on each element to estimate the average normal strain $\Delta \varepsilon$ given by Eq. (1) and used in the initiation and propagation laws:

$\Delta \varepsilon=\frac{\Delta \sigma}{E}$

where $E$ is the material's Young modulus. Afterward, an important geometrical assumption is associated to the finite-element mesh 
definition: cracks can arise on a pre-directed and pre-sized 3D array in four directions. This simplification of the model is justified because experimentally observed cracks are perpendicular to the loading axis in the case of tensile tests and largely oriented in two perpendicular directions in the case of biaxial thermal fatigue tests. In the model, this geometrical assumption comes from the fact that the sample geometry is modeled by 3D finite elements which represent the volume of the sample and 2D vertical cohesive elements between 3D elements which describe cracks or potential cracks. Hence, horizontal cracks are excluded. This is justified by the fact that horizontal cracks are not observed experimentally with the loading conditions considered herein. Moreover, crack initiation is only observed at the free surface of the sample experimentally, so the model simply permits initiation at this location. A representation of the mesh used to model fatigue sample is given in Fig. 1.

Finally, to avoid preferential crack initiation direction (especially for biaxial loadings), the initiation law is the same for both kinds of cohesive elements (of length $c$ and $\frac{c}{\sqrt{2}}$ in Fig. 1). On the other hand, for crack propagation, mesh size dependence has to be introduced (see Section 3).

\subsubsection{Overview of the principal constitutive equations}

The model's constitutive equations, in conjunction with the model's algorithm described in Section 2.2, describes the stepby-step evolution of the Jth cohesive element at the Ith step. The firsts of these mechanical equations are the static equilibrium condition and the linear elastic behavior which give access to the stress and strain of the sample when loaded with a given set of boundary conditions.

The cumulative damage equation describing the damage $\left(D_{I}^{J}\right)$ of a cohesive element after several loading cycles is of the type $[17,18]$.

$D_{I}^{J}=\sum_{i=1}^{I} \frac{N_{i}}{N_{f_{i}}^{J}}$

where $N_{f_{i}}^{J}$ is the number of cycles to break the $J$ th cohesive element at the $i$ th step and $N_{i}$ is the number of cycles at the $i$ th step. Implementing this law into the model is done in Eq. (6). The computation of $N_{f i}^{J}$ depends on if the cohesive element propagates or initiates a crack. As a matter of fact, there is a crack initiation law (3) and a crack propagation law (4) for both phenomenon (The implementations of these laws are detailed in (16) and (10)):

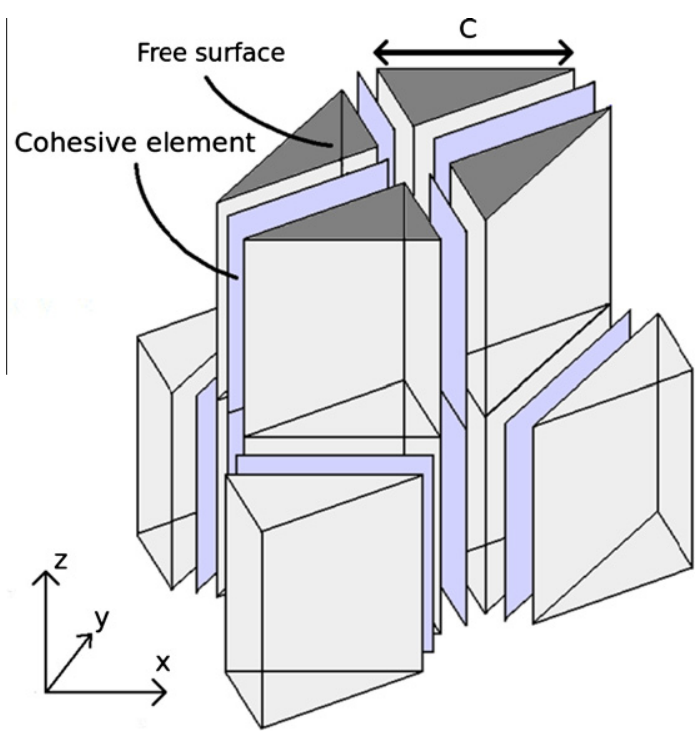

Fig. 1. Prismatic elements meshing.
$N_{f_{i}}^{J}=f_{i n}\left(\Delta \varepsilon_{i_{i}}^{J}, \xi_{i}^{J}\right)$

$N_{f_{i}}^{J}=f_{p r}\left(\Delta \varepsilon_{i}^{J}\right)$

where $\Delta \varepsilon_{i}^{J}$ represents the strain normal to the Jth cohesive element and $\xi_{i}^{J}$ is a random failure parameter. The governing equation of this last parameter is given by its cumulative distribution function, $\mathcal{F}_{\text {cum }}\left(\xi_{i}^{J}\right)$, detailed in (17). Finally, the last constitutive equation is a very simple cohesive behavior describing the stiffness of the cohesive elements $\left(\kappa_{i}^{J}\right)$.

$\kappa_{i}^{J}= \begin{cases}\infty & \text { sound element } \\ 0 & \text { broken element }\end{cases}$

\subsection{Presentation of the algorithm}

This section details different stages of the iterative fatigue algorithm. First, a random damage variable $(\xi)$ is attributed to each cohesive element of the free surface; this represents its resistance to crack initiation. For a given step, the stress field is first obtained from a linear finite element solution. Then it is used to compute the number of cycles to break the next cohesive element ((2), (3), and (4)) and the position of this element. The additional numbers of cycles to failure ((3) and (4)) are evaluated for all cohesive elements and the smallest of all is kept. This detects the weakest element, that is to say the next element to fail. The stiffness of this element then vanishes (5) before the beginning of a new step. The algorithm finishes when a stop condition, i.e. a predetermined maximum number of cycles or a maximum number of broken elements, is reached. A global presentation of this algorithm is given in Fig. 2 and each step is detailed subsequently.

\subsubsection{Initialization and strain computation}

First of all, the sample geometry is built from elementary square bricks presented in Fig. 1. In order to limit computation time, all the simulations presented in this paper are carried out with cubes measuring $(400 \mu \mathrm{m})^{3}$. Hence the dimensions of the cohesive elements are $400 \mu \mathrm{m} \times 400 \mu \mathrm{m}$ for the ones around the cube and $\frac{400}{\sqrt{2}}(\cong 283 \mu \mathrm{m}) \times 400 \mu \mathrm{m}$ for its diagonals. Subsequently, mechanical properties are assigned to each element. For fatigue simulations presented herein, the mechanical properties are set to AISI $304 \mathrm{~L}$ steel: Young modulus (E) $196 \mathrm{GPa}$ (at room temperature) and Poisson ratio $(v)$ 0.3. The stiffness of the cohesive elements is fixed to the maximal value allowed by the CAST3M finite element code (used in this study and available online at www-cast3m.cea.fr): $10^{23} \mathrm{~N} \mathrm{~m}^{-3}$. At the beginning of the simulation, a random failure parameter, $\xi$, is also generated for each cohesive element on the free surface. These parameters aid in determining the crack initiation element (details in Section 3). Afterwards, the mesh is submitted to different types of loading: (1) a uniaxial stress applied at the boundary (Section 3); or (2) a biaxial thermal stress field applied to the whole volume (Section 4). The load magnitude is half of load variation applied on the sample during a cycle. Linear finite elements are used to compute the stress field on the system and to estimate each cohesive element's mean normal strain $(\Delta \varepsilon$, see Eq. (1)). This comes into play in the initiation and propagation laws, detailed in Section 3.

\subsubsection{Classification of cohesive elements}

Initiation or propagation laws use as input the element's connectivity to the surface or to a previously cracked element and outputs the number of cycles to failure for each element. Thus, a geographical classification of the cohesive elements is necessary. The elements are classified into four groups depending on their neighborhood: (1) broken elements (Crack Area, CA); (2) elements 


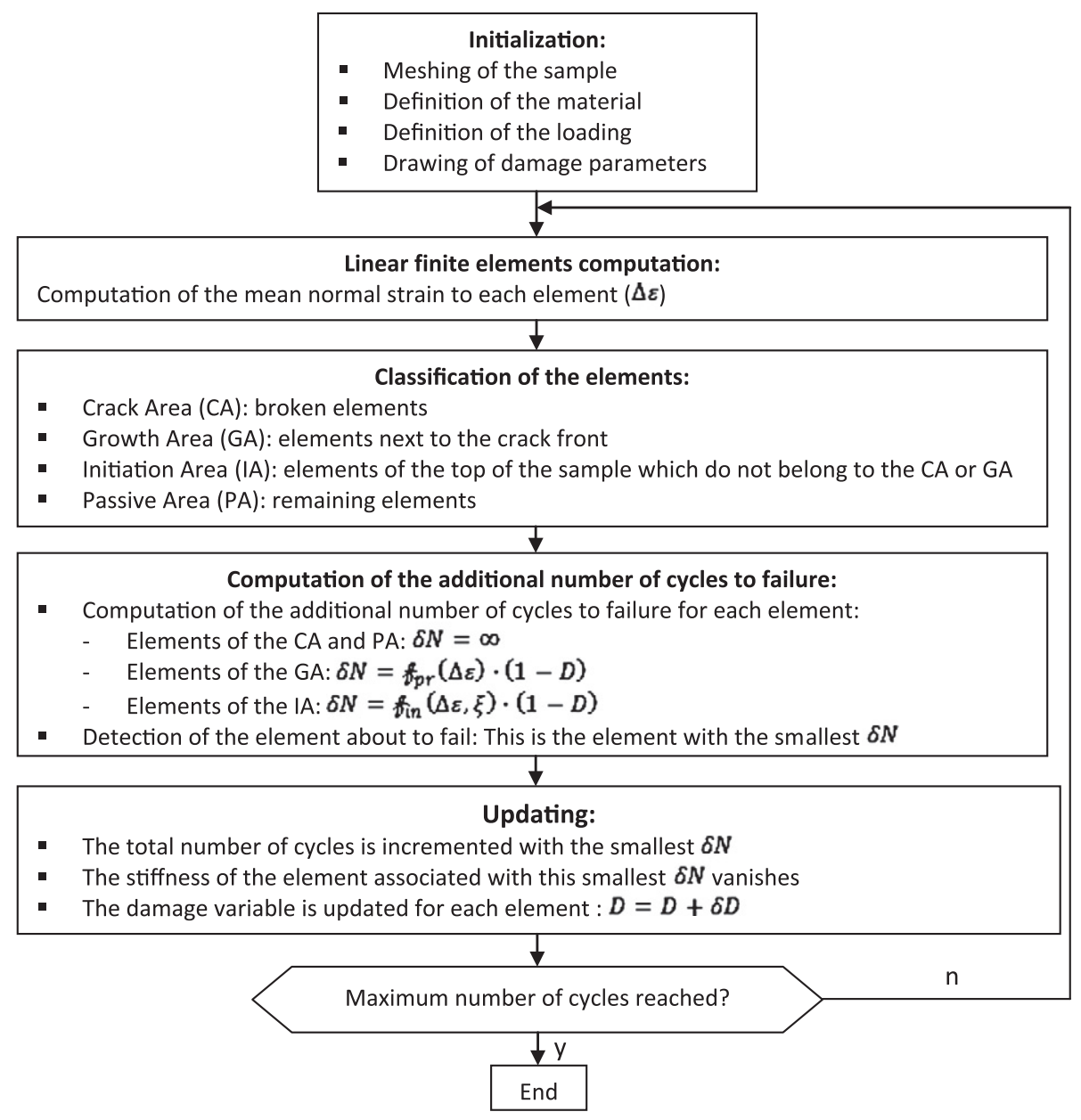

Fig. 2. Fatigue algorithm.

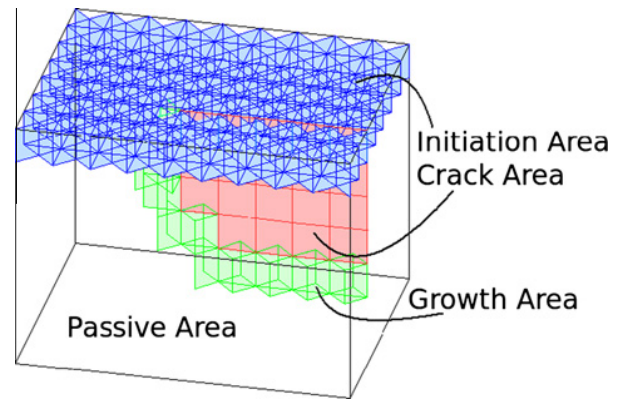

Fig. 3. Illustration of differentiated areas.

which are candidates for initiating a crack (Initiation Area, IA); (3) elements which are candidates for propagating a crack (Growth Area, GA); and (4) elements which will not evolve (Passive Area, PA). These areas are illustrated in the case of a propagating crack in Fig. 3.

To insulate these different areas, given the CA, one begins by determining the GA elements: these elements are connected to the crack tips. Then, IA elements are element on the surface which are not already included in the GA or CA classification. At last, the PA collects the remaining elements.

2.2.3. Computation of the additional number of cycles to failure and detection of the weakest element

Afterwards, cohesive elements are sorted into each area. For each cohesive element, an additional number of cycles to failure $(\delta N)$ is evaluated to detect the weakest element (i.e. the next element to fail). Indeed, this computation depends on area's location. First, if the element belongs to the PA, its additional number of cycles to failures is arbitrarily fixed to infinity $(\delta N=\infty)$. For GA elements, the algorithm computes its number of cycles to failure via propagation laws. These laws are dependent on the mean normal strain on the element $\left(f_{p r}(\Delta \varepsilon)\right)$. Integrated damage, i.e. damage due to previous fatigue cycles steps, is modeled via a damage parameter, $D$. $D$ is evaluated with a linear cumulative damage law. Hence for the Jth element at the Ith step:

$\underbrace{\sum_{i=1}^{I-1} \frac{\delta N_{i}^{\text {weakest }}\left(\Delta \varepsilon_{i}^{J}\right)}{f_{\operatorname{pr}}\left(\Delta \varepsilon_{i}^{J}\right)}}_{D_{I}^{J}}+\frac{\delta N_{I}^{J}}{f_{\operatorname{pr}}\left(\varepsilon_{I}^{J}\right)}=1$

with $\delta N_{i}^{\text {weakest }}=\min _{j} \delta N_{i}^{j}$ at the $i$ th step or rewriting in a more condensed way for each element at each step:

$\delta N=f_{p r}(\Delta \varepsilon) \cdot(1-D)$

In other words, $D$ records the history of the elements. Initially it is zero for every element, subsequently it increases during each step, as described in Eq. (9). Similarly, the additional number of cycles to failure for an element of the IA is computed from the initiation law which depends on the mean normal strain on the element and on its random failure parameter $\left(f_{\text {in }}(\Delta \varepsilon, \xi)\right)$ (see Section 3). Moreover, just like the GA elements, the integrated damage is taken into account as follows: 


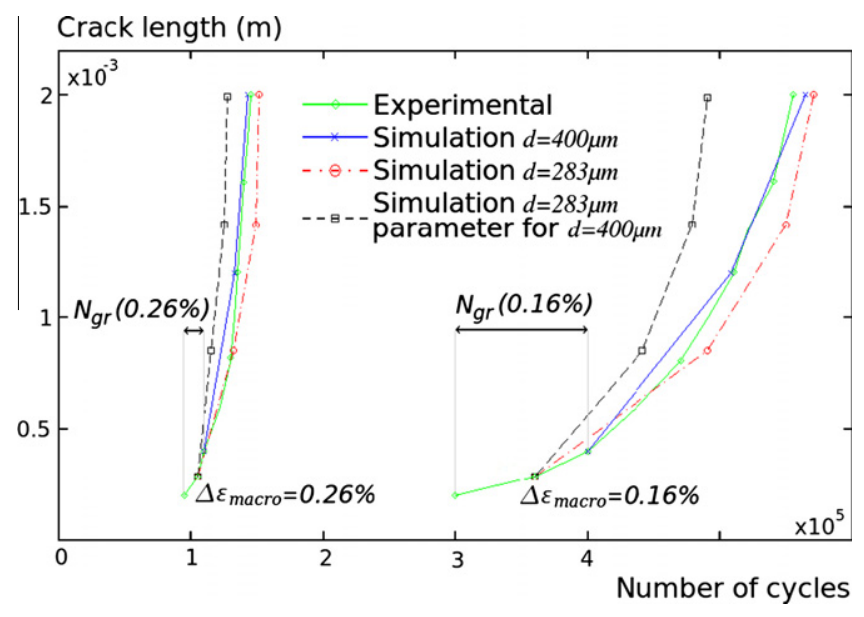

Fig. 4. Computed and experimental [16] growth curves for $283 \mu \mathrm{m}$ and $400 \mu \mathrm{m}$ cohesive elements. The blue curve: $300 \mu \mathrm{m}$ elements and a set of identified propagation parameters $\left(k_{p r}^{400}\right.$ and $\left.\gamma_{p r}^{400}\right)$. Black curve: $283 \mu \mathrm{m}$ elements and identical propagation parameters $\left(k_{\mathrm{pr}}^{400}\right.$ and $\left.\gamma_{\mathrm{pr}}^{400}\right)$. Red curve: $283 \mu \mathrm{m}$ elements with propagation parameters derived from relation (15) and $\left(k_{p r}^{400}\right.$ and $\left.\gamma_{p r}^{400}\right)$. (For interpretation of the references to color in this figure legend, the reader is referred to the web version of this article.)

$\delta N=f_{\text {in }}(\Delta \varepsilon, \xi) \cdot(1-D)$

From all additional number of cycles $(\delta N)$ of the cohesive elements, the smallest is isolated $\left(\delta N^{\text {weakest }}\right)$. This represents the number of cycles performed at this step and permits to compute the incremental damage for each element at the considered step:

$\delta D=\frac{\delta N^{\text {weakest }}}{N_{f}}$

where $N_{f}$ is the number of cycles to failure. $N_{f}=f_{p r}(\Delta \varepsilon)$ or $N_{f}=f_{\text {in }}(\Delta \varepsilon, \xi)$ depending where the element is located.

\subsubsection{Updating}

The total number of cycles of the simulation is incremented with the minimum additional number of cycles to failure $\left(\delta N^{\text {weakest }}\right)$. Besides, the element associated with this last number of cycles is the element which fails at this step. Therefore, its stiffness is set to $1 \mathrm{~N} \mathrm{~m}^{-3}$ and the damage of each element is incremented of $\delta D$ as defined in (9). Finally, updated mechanical properties are used as an input of the next iteration.

\section{Application to uniaxial mechanical fatigue}

The model described in Section 2 is now applied to model uniaxial mechanical fatigue tests. Propagation and initiation laws are

\section{Crack density $\left(1 / \mathrm{m}^{2}\right)$}

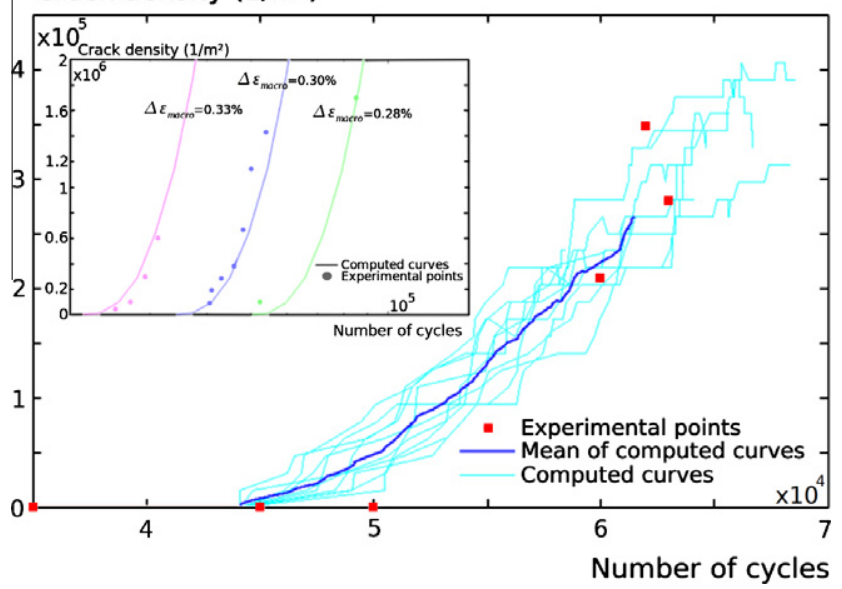

Fig. 6. Experimental and computed crack density curves (and their mean curve) for $400 \mu \mathrm{m}$ length elements, a $0.30 \%$ strain load and a threshold detection of $400 \mu \mathrm{m}$ for experimental results. Inset: experimental [16] and simulated (neglecting propagation) crack density evolutions for three different loadings and with a threshold detection of $200 \mu \mathrm{m}$.

explicitly defined and parameters of these laws, separately identified from experimental results, are given. Then, complete simulations including both initiation and propagation are performed and compared to the experimentations. Finally, two important phenomena for the development of crack network are studied: shielding effect and crack coalescence.

\subsection{Crack propagation}

The crack propagation law is applied to the GA elements (Section 2.2.2). It gives the number of cycles to failure for an initially undamaged element of length, $d$ (herein $d=400 \mu \mathrm{m}$, or $283 \mu \mathrm{m}$ for diagonal elements, cf. Fig. 1), and is calculated by the following propagation law:

$N_{f}=f_{p r}(\Delta \varepsilon)=k_{p r}^{d} \cdot \Delta \varepsilon^{-\gamma_{p r}^{d}}$

where $\Delta \varepsilon$ is the mean normal strain on the cohesive element evaluated from Eq. (1) and $k_{p r}^{d}$ and $\gamma_{p r}^{d}$ are propagation parameters dependent on the element length for two reasons. First, they are parameters of a law which gives the number of cycles to increase by a length crack of $d$. Second, as the mean normal strain evaluated at the crack tip depends on the size of the element, $k_{p r}^{d}$ and $\gamma_{p r}^{d}$ should also depend on $d$ in order to avoid any mesh sensitivity or any favored propagation direction (since diagonal elements are smaller). Invoking fundamental hypothesis about the geometry and the stress field around the crack tips, a size dependence of
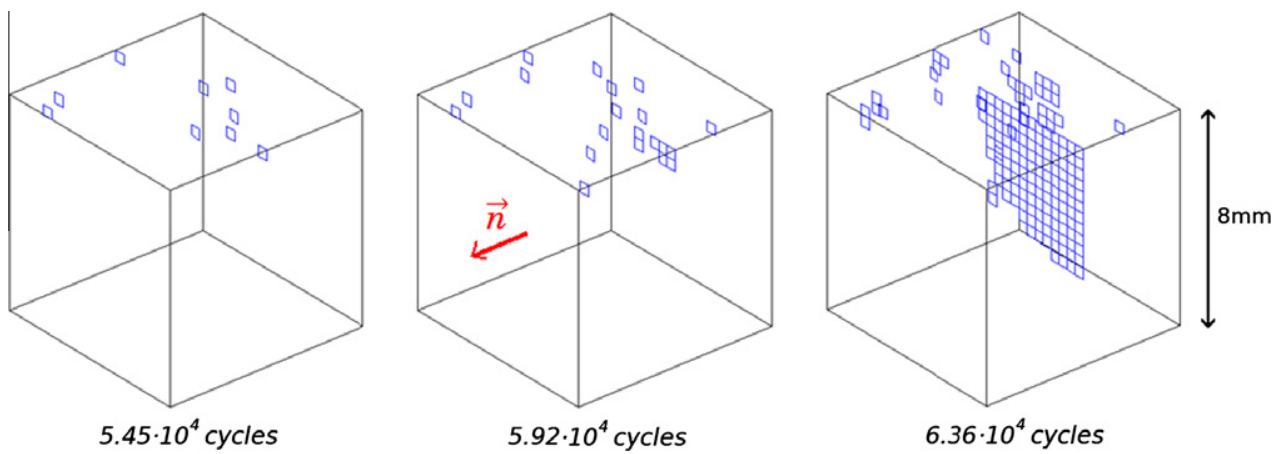

Fig. 5. Cracking morphologies obtained with uniaxial strain fatigue simulation at $0.30 \%$ (3D view). 


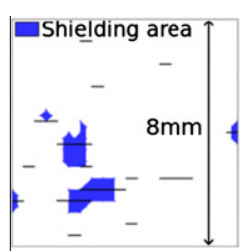

Amplification area

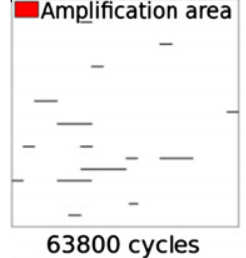

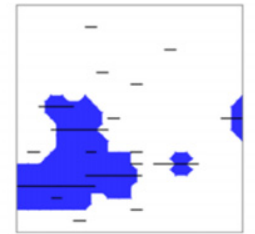

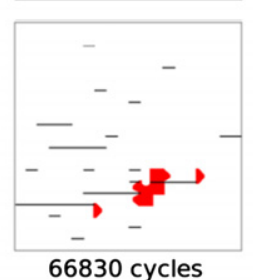

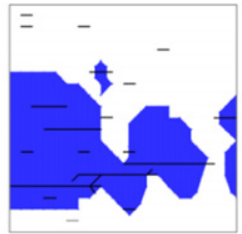

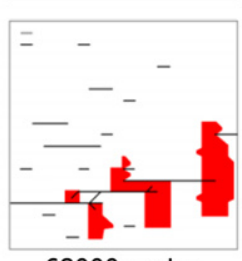

68000 cycles
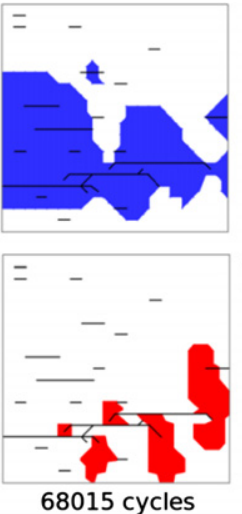

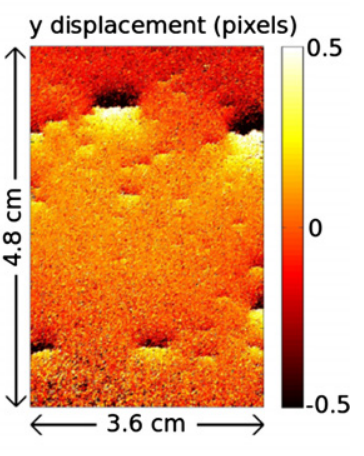

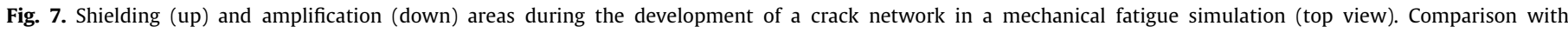

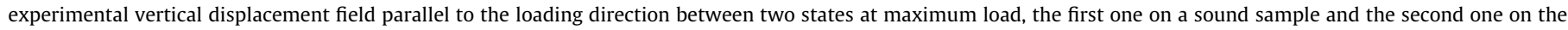
damaged one. Shielding areas can then be revealed through the displacement gradient they introduce [16].

the propagation parameters can be derived from Paris' law (11) in opening mode (mode I).

$\frac{d a}{d N}=\kappa \cdot \Delta \mathcal{K}_{I}^{\mu}$

where $\kappa$ and $\mu$ are constant, $\Delta \mathcal{K}_{I}$ is the variation of the SIF in mode I propagation and $d a$ is the crack growth corresponding to $d N$ cycles. Hypothesizing that the crack shape is simple enough, the stress field normal to the crack plane can be written as a function of the distance to the crack tip, $r$ [19]:

$\Delta \sigma(r)=\frac{\Delta \mathcal{K}_{\mathrm{I}}}{\sqrt{2 \pi r}}$

Consequently, the average normal stress applied on an element of length $d$ at the crack tip is approximately:

$\Delta \sigma=\frac{1}{d} \int_{0}^{d} \Delta \sigma(r) d r=\frac{2 \Delta \mathcal{K}_{\mathrm{I}}}{\sqrt{2 \pi d}}$

This approximation is valid because $d$ is chosen sufficiently small such that $\Delta \mathcal{K}_{I}$ (and consequently $\Delta \sigma$ ) remains constant during the crack propagation over an element. Introducing Eq. (13) and the stress-strain relation defined in (1) into Paris' law (11), one can thus compute the number of cycles for this crack propagation:

$N_{f}=\int_{0}^{N_{f}} d N=\int_{0}^{d} \frac{1}{\kappa}\left(\frac{\sqrt{2 \pi d}}{2} \cdot \Delta \sigma\right)^{-\mu}$
$\mathrm{da}=d^{1-\frac{\mu}{2}} \cdot \frac{(E \sqrt{2 \pi})^{-\mu}}{2^{-\mu} \kappa} \cdot \Delta \varepsilon^{-\mu}$

Thus, comparing (10) and (14) the propagation parameters can be expressed as functions of the cohesive element length:

$\left\{\begin{array}{l}k_{p r}^{d}=d^{1-\frac{\mu}{2}} \cdot \rho \\ \gamma_{p r}^{d}=\mu\end{array}\right.$

where $\rho=\frac{(E \sqrt{2 \pi})^{-\mu}}{2^{-\mu_{K}}}$ is a constant since $\mu$ (and so $\gamma_{p r}^{d}$ ) does not depend on the element size. These constants $\left(k_{p r}^{400}=1.55 \times 10^{-4}\right.$ cycles and $\left.\gamma_{p r}^{400}=3.30\right)$ are fitted for $d=400 \mu \mathrm{m}$, independently of initiation, with experimental results presented in [16]. This choice is done because of the numerous assumptions used in these calculations. These experiments consist in stretching uniaxial fatigue samples made of AISI 304L stainless steel with a sine-wave loading (5 Hz frequency, $R=-1$ ) in a servo hydraulic testing machine. Crack initiation is detected using a Digital Image Correlation technique between two pictures of the sample taken at maximum load, the first one on the sound sample and the second one on the damage one (see also an example of experimental crack network in Fig. 7). Fitting is done through numerical simulations considering a unique crack propagating in the middle of the surface of a cube $(8 \mathrm{~mm} \times 8 \mathrm{~mm} \times 8 \mathrm{~mm}$ with a mesh size of $400 \mu \mathrm{m})$ loaded by a uniaxial stress. As shown in Fig. 4 (green and blue curves), this is in very good agreement with experimental results which validates the form of the propagation law (10). It is also verified, applying relation (15) with measured parameters of the Paris' laws $\left(\mu=3.31, \kappa=4.18 \times 10^{-32} U S I\right.$, from [20]) that directly computed $\tilde{k}_{p r}^{400}$ and $\tilde{\gamma}_{p r}^{400}$ are close to the one fitted $\left(\tilde{k}_{p r}^{400}=1.16 \times 10^{-4}\right.$ cycles and $\left.\tilde{\gamma}_{p r}^{400}=3.31\right)$. This good agreement reveals that a direct evaluation of $\tilde{k}_{p r}^{d}$ and $\tilde{\gamma}_{p r}^{d}$ would have also provided satisfying results.

The efficiency of relation (15) to reduce the mesh sensitivity is evidenced in Fig. 4 from additional simulations performed with a mesh size of $283 \mu \mathrm{m}$. The black curve does not account for relation (15) and keeps $k_{p r}^{400}$ and $\gamma_{p r}^{400}$ for the simulation. The comparison with the blue curve exhibits a sharp increase of the propagation rate induced by the mesh size refinement. The red curve uses $k_{p r}^{283}=1.94 \times 10^{-4}$ cycles and $\gamma_{p r}^{283}=3.30$ evaluated from relation (15) and the values of $k_{p r}^{400}$ and $\gamma_{p r}^{400}$ : the good agreement with the blue curve denotes a very limited mesh size sensitivity using Eq. (15).

\subsection{Crack initiation}

The shape of the initiation law comes from considerations when studying results of crack initiation fatigue experiments with crack size at initiation equal to $200 \mu \mathrm{m}[16,20]$. It gives the number of cycles to failure for an IA element of fixed length as a function of $\xi$ and of the averaged normal strain on this element:

$N_{f}=f_{\text {in }}(\Delta \varepsilon, \xi)=k_{0} \cdot\left(\Delta \varepsilon-\Delta \varepsilon_{0}\right)^{-\gamma_{0}} \cdot \xi+N_{\text {gr }}(\Delta \varepsilon)$

where constants, $k_{0}=383.7$ cycles, $\gamma_{0}=2.18$ and $\Delta \varepsilon=1.75 \times 10^{-3}$, are fitted with macroscopic fatigue curves [21]. $N_{g r}$ is a function of the normal strain and represents the number of cycles to propagate an initiated crack from length $200 \mu \mathrm{m}$ to $400 \mu \mathrm{m}$ (corresponding to the size of the element).

$\xi$ is a random failure parameter $(\xi \geqslant 1)$ introduced to account for the randomness of crack initiation. This parameter follows a Weibull distribution whose cumulative distribution function is given by the following equation:

$F_{\text {cum }}^{\alpha, \beta}(\xi)=1-e^{-\left(\frac{\xi-1}{\beta}\right)^{\alpha}}$

where $\alpha$ and $\beta$ represent initiation parameters and are the parameters of the Weibull distribution for cohesive elements of length $200 \mu \mathrm{m}$. This law providing positive failure parameters has been 
Table 1

Parameters for the numerical simulations.

\begin{tabular}{lll}
$E=196 \mathrm{GPa}$ & $v=0.3$ & $d=400 \mu \mathrm{m}$ \\
$K_{0}=383.7$ cycles & $\gamma_{0}=2.18$ & $\Delta \varepsilon=1.75 \times 10^{-3}$ \\
$k_{g r}=1.19 \times 10^{-6}$ & $\gamma_{g r}=3.913$ & $k_{p r}^{400}=1.55 \times 10^{-4}$ cycles \\
$\quad$ cycles & & $\alpha=1.91 ; \beta=2.52$ \\
$\gamma_{p r}^{400}=\gamma_{p r}^{283}=3.3$ & $k_{p r}^{283}=1.94 \times 10^{-4}$ cycles & \\
\hline
\end{tabular}

used for the sake of simplicity, but more complex ones can be found in [16]. In spite of this simplicity, it agrees excellently with experimental data (as presented in Fig. 6 insert). The first term of the right hand side of (16) just gives the number of cycles to initiate a crack $200 \mu \mathrm{m}$. $N_{\text {gr }}$ corrects this result for a crack of length $400 \mu \mathrm{m}$. This additional number of cycles is related to the average normal strain on the IA element (Section 2.2.2) following:

$N_{g r}(\Delta \varepsilon)=k_{g r} \cdot \Delta \varepsilon^{-\gamma_{g r}}$

where $k_{g r}$ and $\gamma_{g r}$ are constant parameters fitted independently of initiation via the experimental growth curves given in Fig. 4. Note: this propagation law imbedded in the initiation law must not be confused with the propagation law evaluated for GA elements (Section 2.2.2; Eq. (10)). Indeed, Eq. (10) is for GA elements, i.e. located at the crack tip, whereas Eq. (18) is applied for a propagating GA element whose size $(200 \mu \mathrm{m})$ is less than the size of an element. Finally, identified parameters are: $k_{g r}=1.19 \times 10^{-6}$ cycles and $\gamma_{g r}=3.913$. Then, the random failure parameters are initially drawn for each cohesive element related to the free surface (i.e. elements which are candidate for initiation). The couple of initiation parameters $(\alpha=1.91$ and $\beta=2.52)$ is fitted with crack density evolution curves obtained with the same experimental device as the one described previously ([16], Fig. 6 inset). Fitting is carried out through numerical simulations (avoiding propagation) with an element length $d=200 \mu \mathrm{m}$ corresponding to the crack detection threshold in experiment. As mentioned in Section 2.1, it is important to note that the same parameters are used for both element lengths (283 $\mu \mathrm{m}$ and $400 \mu \mathrm{m}$ ) and do not favor any initiation direction.

\subsection{Comparison with the experiment}

In this section, the whole mechanical fatigue model combining initiation and propagation is tested through comparisons with experimental crack density evolution curves. Indeed, the algorithm and its parameters (gathered in Table 1) are run with a numerical sample of dimension $8 \times 8 \times 8 \mathrm{~mm}^{3}$ under a uni-axial stress $\left(\Delta \sigma_{\text {macro }}\right)$ corresponding to a uniaxial strain $\left(\Delta \varepsilon_{\text {macro }}\right)$ of $0.30 \%$ in the $\vec{n}$ direction, which is the only result available in post-treated experimental data with a crack detection of $400 \mu \mathrm{m}$ [16].

First, evolution of the element failure within the sample is given at three different steps in Fig. 5. These three steps illustrate the three phases which are commonly observed during a mechanical fatigue experiment [16]. First, isolated small cracks randomly initiate on the free surface of the sample. These isolated cracks continue to nucleate, however, some of them begin to slowly propagate. Finally, one crack becomes the dominant crack and it prevents the initiation and the propagation of other cracks. This qualitative result clearly reproduces the competition between initiation and propagation as observed experimentally. The model was verified during 10 different independent numerical simulations (different failure parameter drawings). Experimental crack density curves and numerical ones along with the mean of the numerical curves are compared in Fig. 6.

The numerical results are quantitatively in agreement with the experimental ones. The sharp fluctuations of the curves, corresponding to the numerical results, represent the initiation of a new crack or the merging of two of them. Moreover, around $6.2 \times 10^{4}$ cycles, curves saturate. This corresponds to the end of the second phase described in Fig. 5: crack initiation ceases when the dominant crack takes over. A few crack density curves even decrease which is related to the phenomenon of crack coalescence.

\subsection{Crack coalescence and shielding effect}

The purpose of this section is to show how the numerical fatigue model is able to reproduce two important phenomena arising during the development of a fatigue crack network: crack coalescence and shielding effects.

\subsubsection{Shielding and amplification effects}

First, to study the evolution of the shielding area, simulations performed in Section 3.3 are used. The shielding area $\left(\mathcal{A}_{\text {shield }}\right)$ is the surface of the sample where the local loading is reduced around preexisting cracks in comparison with macroscopic loading, so that cracks cannot initiate nor grow. At each step, the shielding area can be defined by the cohesive elements (excepted those in the direction of loading) having their normal strain smaller than $K_{s h}$ times the applied macroscopic strain:

$\mathcal{A}_{\text {shield }}=\left\{\right.$ Elem $\left._{l} \mid \Delta \varepsilon_{l} \leqslant K_{\text {sh }} \cdot \Delta \varepsilon_{\text {macro }}\right\}$

Conversely, the amplification area $\left(\mathcal{A}_{\text {ampli }}\right)$ is a surface where the local loading is amplified in comparison with the macroscopic one. It is defined as the area which embodies the elements whose normal strain is bigger than $K_{a m p}$ times the applied macroscopic strain:

$\mathcal{A}_{\text {ampli }}=\left\{\right.$ Elem $\left._{l} \mid \Delta \varepsilon_{l} \geqslant K_{\text {amp }} \cdot \Delta \varepsilon_{\text {macro }}\right\}$

Following these definitions, the results presented in Fig. 7 are given for $K_{s h}=0.5$ and $K_{a m p}=1.5$. They show that cracks do not grow or initiate in the shielding area and they preferably grow in the amplification area as expected.

The numerical results are not directly comparable with experimental ones. However, it has been shown numerically [22] that areas where the stress field heavily decreases next to a crack are similar to areas where the displacement gradient is high. Thus, the right side of Fig. 7 presents such an experimental displacement field [16] in order to compare it with the shape of shielding areas that appear from the simulation. To conclude, these results clearly exhibit that the model can reproduce shielding and amplification effects which are in qualitative agreement with experimental results.

\subsubsection{Coalescence of two cracks}

To study the coalescence of two cracks, the geometry, the material and the applied load are the same as the one used in Section 3.3 and presented in Fig. 5. Nevertheless, only two chosen cracks are initiated at the surface of the sample. The coalescence phenomenon is then studied as a function of the orthogonal distance between these two cracks (l). The crack coalescence simulations have been carried out for $l$ equals to $0 \mu \mathrm{m}, 400 \mu \mathrm{m}$ and $800 \mu \mathrm{m}$. For these different values, the crack morphologies are explored at a step just before the total coalescence of both cracks. The results are presented in Fig. 8.

These results exhibit that the model is able to reproduce, at least qualitatively, the eye shape observed experimentally in mechanical [16] and thermal [20] fatigue experiments. However, inaccuracies appear on the last numerical coalescence test, for $l$ equal $800 \mu \mathrm{m}$. Indeed, a first coalescence crack appears and does not grow; then another one arises farther and propagates. These problems may come from the fact that the model just takes into account the mode one propagation whereas in this configuration mode two should prevail. 

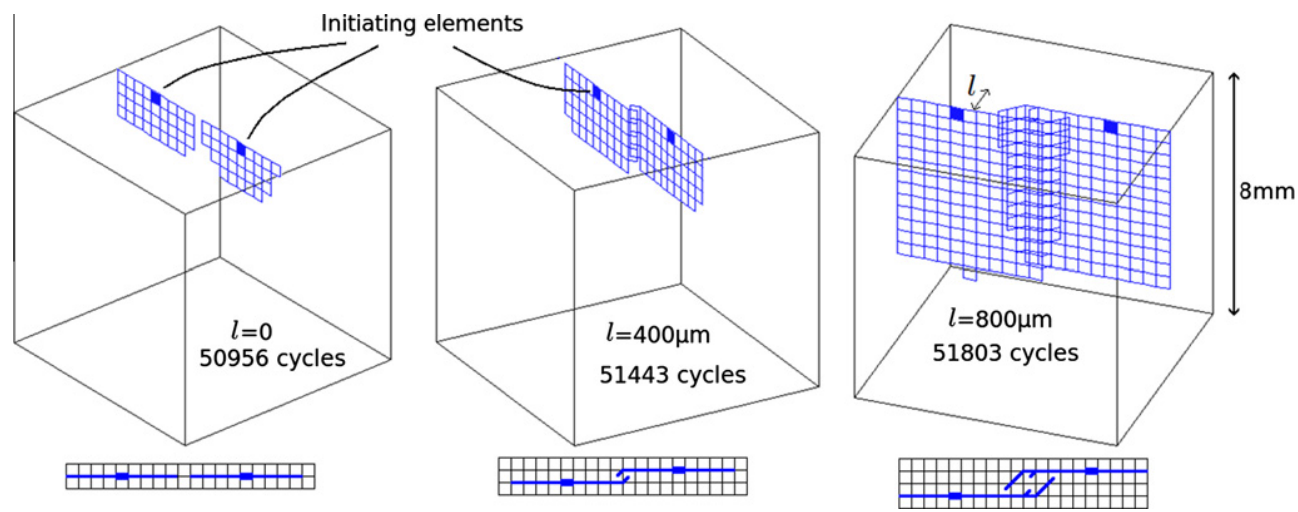

Fig. 8. Crack coalescence morphologies (3D and partial top view).

\section{Application to thermal fatigue}

The purpose of Section 4 is to evaluate the proposed model ability to reproduce crack networks observed in thermal fatigue [5]. Thermal loading inspired from the SPLASH experiment developed at CEA [5] is used to derive the temperature field [23]. The associated mechanical loading used in the fatigue simulation is derived from the temperature field, evaluated at the end of a cycle, according to a thermo-elastic simulation (the thermal strain field associated to the temperature field being used as simulation input). As the thermal loading has only been evaluated once on a sound material, hence there is no coupling modeled herein between the evolution of the crack network and the temperature field. In addition the thermo-elastic simulations rely on a static analysis and dynamic effects involved during the thermal cycling loading are assumed to be negligible.

\subsection{Definition of the thermo-mechanical loading}

\subsubsection{Thermal analysis}

The geometry of the sample and the thermal loading are inspired from the SPLASH device [5] (Fig. 9) even though the purpose of this paper is not to reproduce precisely this complex experiment. This experiment consists in heating an austenitic stainless steel (AISI 304L) bar of $20 \mathrm{~cm}$ length, $2 \mathrm{~cm}$ wide and $3 \mathrm{~cm}$ high by a joule effect and quenching it cyclically with a water spray on two windows located in the middle of two opposite faces. To compute the temperature field variation during a quenching cycle, the specimen is modeled with cubic finite elements whose thermomechanical properties are given in Table 2 [10].

Only qualitative results on the development of thermal fatigue crack networks are searched for in this preliminary study. Consequently and for sake of simplicity, the temperature dependence of parameters listed in Table 2 is not accounted for in the simulations. The uniform heating due to the Joule effect is taken into

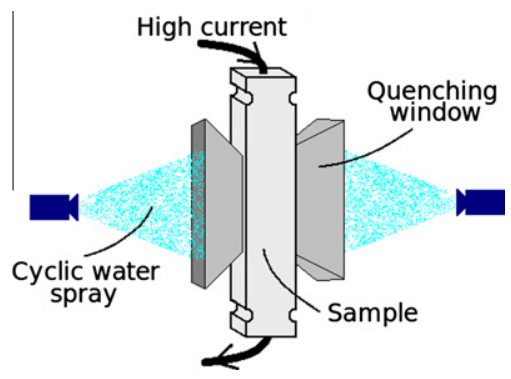

Fig. 9. Schematic view of the SPLASH experiment device [5].
Table 2

Thermo-mechanical properties of the sample on the studied temperature domain.

\begin{tabular}{ll}
\hline Young modulus $(E)$ & $175 \mathrm{GPa}$ \\
Poisson's ratio $(v)$ & 0.3 \\
Density & $7800 \mathrm{~kg} \mathrm{~m}^{-3}$ \\
Specific heat & $500 \mathrm{~J} \mathrm{~kg}^{-1} \mathrm{~K}^{-1}$ \\
Thermal conductivity & $19 \mathrm{~W} \mathrm{~m}-1$ \\
Coefficient of the linear thermal expansion & $18 \times 10^{-6} \mathrm{~K}^{-1}$ \\
\hline
\end{tabular}

account by a continuous heat source of $5.5 \times 10^{5} \mathrm{~W} \mathrm{~m}^{-3}$, while a constant heat flux $\left(F_{\text {air }}\right)$ of $-5 \times 10^{3} \mathrm{~W} \mathrm{~m}^{-2}$ leaves the front faces of the specimen to model the air convection. The temperature is fixed at $320^{\circ} \mathrm{C}$ on both end and the quenching is modeled by a time and space variable heat flux $\left(F_{\text {quen }}\right)$ defined over the quenching windows by:

$F_{\text {quen }}(x, y, t)=F_{0}(t) \cdot\left(\cos \left(\frac{\pi x}{\lambda}\right) \cos \left(\frac{\pi y}{\lambda}\right)\right)^{0.2}$

where $\lambda=9 \mathrm{~mm}$ is the window size and $F_{0}$ is a negative periodic function of time given in Fig. 10. The minimum value of this last function is $-2.5 \times 10^{6} \mathrm{~W} \mathrm{~m}^{-2}$ for a temperature variation of $150{ }^{\circ} \mathrm{C}$ over one period $(\Delta T),-3.3 \times 10^{6} \mathrm{~W} \mathrm{~m}^{-2}$ for a temperature variation of $200{ }^{\circ} \mathrm{C}$ and $-4.5 \times 10^{6} \mathrm{~W} \mathrm{~m}^{-2}$ for a temperature variation of $270{ }^{\circ} \mathrm{C}$. Taking advantage of symmetry properties, only one eighth of the sample is modeled for the thermal computation whose initial condition is a uniform temperature field of $320^{\circ} \mathrm{C}$. Thus, adiabatic conditions are applied along the symmetry planes. The geometry and the boundary conditions are summed up in Fig. 10.

\subsubsection{Thermo-mechanical stress analysis}

In order to optimize the thermo-mechanical fatigue simulation the steel sample is modeled by a parallelepiped of dimension $9.2 \times 9.2 \times 2.8 \mathrm{~mm}^{3}$ which corresponds to the domain where the temperature gradient is the highest. It is meshed with prismatic and cohesive elements. A remaining parallelepiped of $2 \times 3 \times 1.5 \mathrm{~cm}^{3}$ is then meshed with coarser cubic elements as presented in Fig. 11.

The temperature field computed in Section 4.1.1 follows the finite element simulation presented in [23]. Moreover, it is projected onto this meshing as shown on a half sample in Fig. 12. Then, another finite element computation acquires the thermal stress field associated with this temperature field assuming stress free boundary conditions on every face. The exception being, the bottom face where a symmetric boundary condition is applied. To justify the dimensions of the finely meshed area, the Von Mises stress field is computed from the thermal stress field for the sound sample (without any crack) as presented in cut view in Fig. 12. Hence, it 


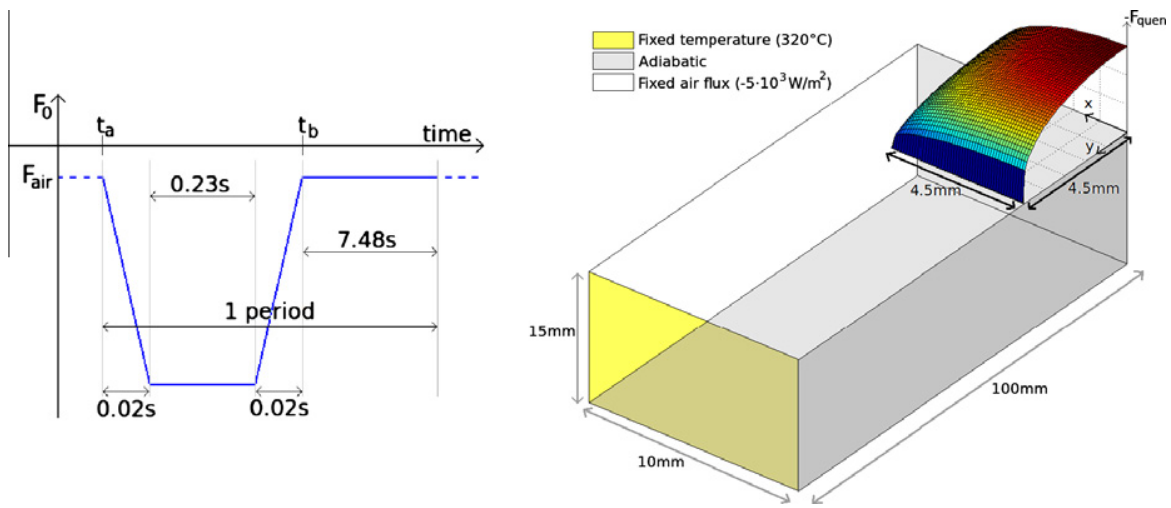

Fig. 10. Variation of the minimum flux in the quenched area during one period (after [23]) and Thermal model of the device.

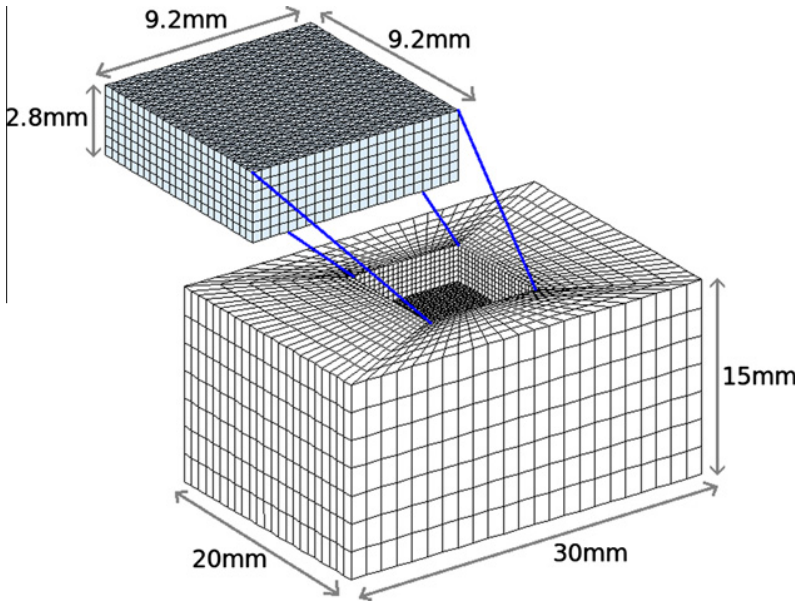

Fig. 11. Thermo-mechanical fatigue meshing.

can be observed that the area of high stress is included into the refined mesh.

\subsection{Thermo-mechanical fatigue}

\subsubsection{Additional Assumptions}

To apply the numerical fatigue model to the case of thermomechanical fatigue, supplementary assumptions are added to the ones given in Section 2.1. The first of them is that the stress field computed from the temperature load $(\Delta T)$ represents the whole variation of the strain over a thermal cycle, hence, just one half of the values of this field is used in the fatigue model to be consistent with what is done in Sections 2 and 3.

Then, the temperature field is computed just once, at the beginning, for a sound sample, decoupling thermal and mechanical interactions. Hence, the thermal behavior of the system is assumed not to depend on the crack network nor on a potential oxide layer appearing at the surface of the quenched area [24]. Then, the propagation and initiation parameters are those identified in Section 3.1 on uniaxial mechanical fatigue tests performed at room temperature. This is obviously a quite rough assumption since these parameters might depend on the temperature.

More importantly, crack initiation and propagation laws presented in Section 3.1 are applied on the values of the strain variation in the loading direction which appears to be the highest value of all components of the strain tensor. In thermal fatigue loadings such as the one simulated here, the equi-biaxial stress at the surface leads to in-plane strain variations smaller than out of plane ones for an elastoplastic material such as austenitic stainless steels [21]. Preliminary experimental results on isothermal equi-biaxial high cycle fatigue tests on this material show a correct correlation with uniaxial results on the strain-fatigue curve of the material providing the maximum strain is compared in both types of tests [25]. An elastoplastic 3D finite element simulation of such equibiaxial fatigue tests, not presented in this paper, allows for estimating that the out of plane strain variation is 1.5 times the in plane strain variation. In the present paper, the material behavior is considered elastic and thus our simulations cannot reproduce this gap between in-plane and out of plane strain variations. However, the in-plane mechanical strain variation estimated from the thermal field is supposed not to depend much on the mechanical behavior of the material (elastic or elastoplastic). Only the out-of plane component should be much more sensitive. Besides, only the in-plane strain variation is exploited during the simulation on the cohesive elements and therefore this strain variation must be amplified by an ad hoc parameter $k$ in order to represent the effect of plasticity in the evaluation of the maximum strain variation in equi-biaxial loadings. Based on the above discussion, this parameter should equal approximately 1.5 .

In order to derive quantitative results on the development of crack networks in 304L stainless steels using the proposed simulation tool, it appears then that elastoplastic simulations are necessary in the future. However, if only qualitative results are required (for instance in order to check for the influence of thermal loading on the crack network density, size of the cracks and so on) preliminary simulations proposed herein are adequate.

\subsubsection{Thermal fatigue laws}

As explained previously, the thermal fatigue laws are derived from the purely mechanical ones proposed and identified in Sections 3 (i.e. multiplying the strain $\Delta \varepsilon$ by $k$ ):

$N_{f}=f_{\text {in }}(k \cdot \Delta \varepsilon, \xi)$

$N_{f}=f_{p r}(k \cdot \Delta \varepsilon)$

The parameter $k$ is fitted with experimental results [26] to get a similar number of cycles to initiation between experiments and simulation for a temperature load of $\Delta T=200^{\circ} \mathrm{C}$. The computation of this parameter is straight forward considering Eq. (22), the maximum strain for $\Delta T=200{ }^{\circ} \mathrm{C}(\Delta \varepsilon)$ and the number of cycles to initiation $\left(N_{f}\right): k=2.8$. The fact that $k>1.5$ as suggested earlier reveals that, even if one uses an elastoplastic set of constitutive equations, the predictions of the experimental number of cycles to crack initiation based on von Mises equivalent strains and Eq. (22) are largely nonconservative [26]. The origin for such a discrepancy is still under investigation and is outside the scope of this paper. 

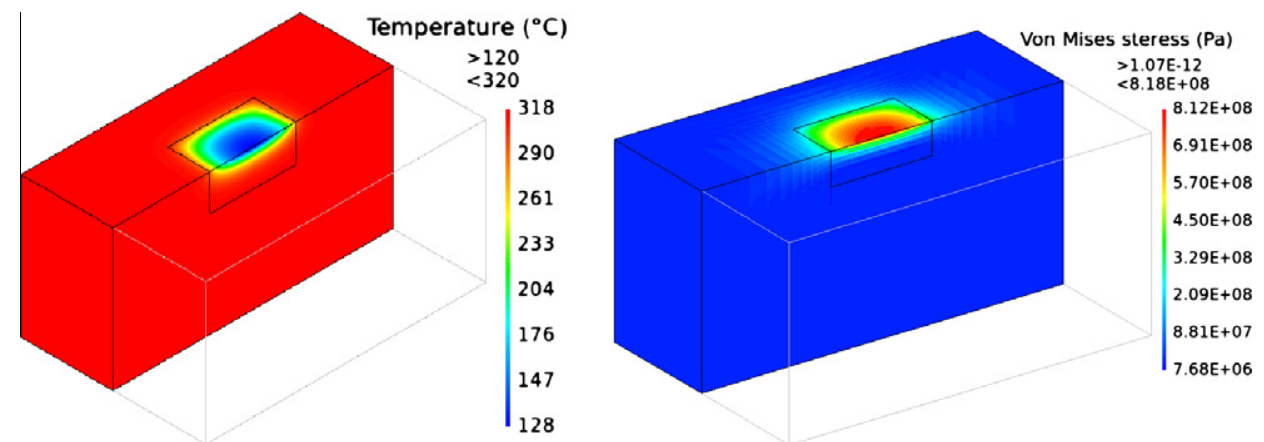

Fig. 12. Temperature field onto the mechanical meshing and Von Mises stress field due to a thermal load of $\Delta T=200{ }^{\circ} \mathrm{C}$ (cut views).

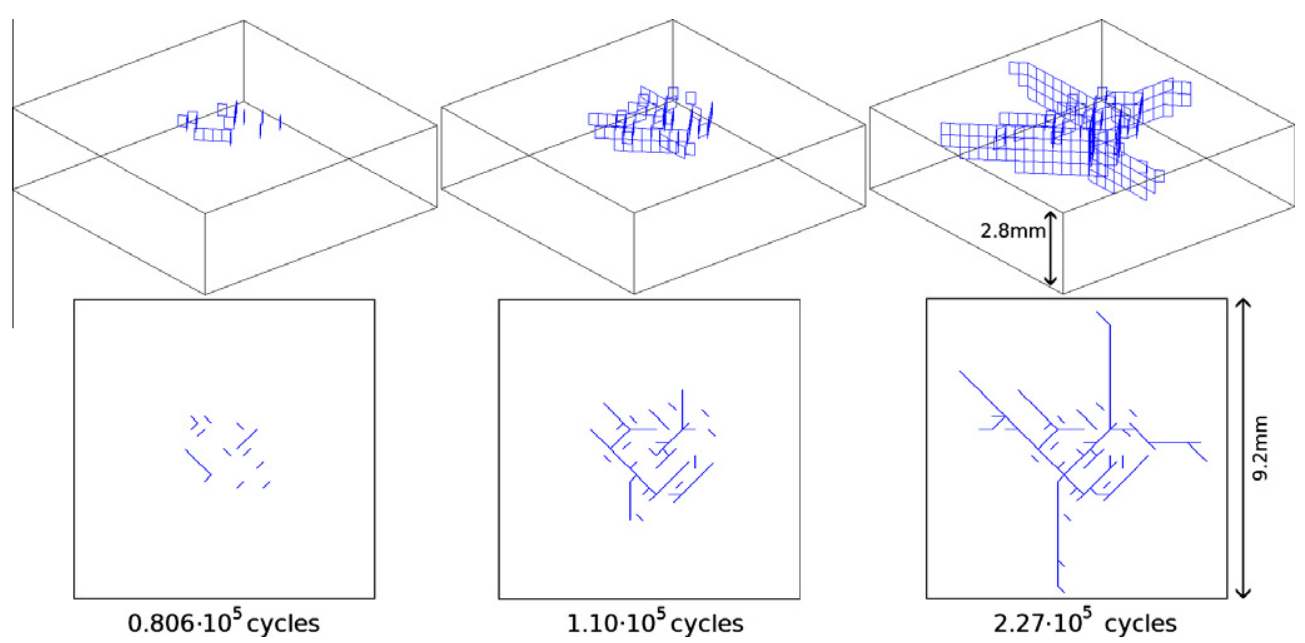

Fig. 13. Crack network evolution for $\Delta T=270{ }^{\circ} \mathrm{C}$ (3D and top views).

\subsubsection{Simulation of thermal crack network development}

Fatigue simulations have been carried out for three temperature loads: $\Delta T$ equaling $270{ }^{\circ} \mathrm{C}, 200{ }^{\circ} \mathrm{C}$ and $150{ }^{\circ} \mathrm{C}$ with a maximum temperature of $320^{\circ} \mathrm{C}$. For these three temperature variations, graphical representations of the crack network evolution are given in Figs. 13-15.

The qualitative evolution of the crack networks is in good agreement with what is observed experimentally. Indeed, for a high temperature load (Fig. 13) a lot of cracks initiate rapidly and then some of them (the firsts which appeared) propagate. Hence, at the end a high number of short cracks are observed. On the contrary, for a low temperature load (Fig. 15), few cracks initiate at the beginning and just a pair of them propagate while keeping shielding cracks from initiating and growing. Thus, at the end of the simulation, a few long cracks are obtained. Similarly, after a certain number of cycles it is possible to note that the cracks are mainly oriented in two perpendicular directions.

Then, for each temperature, five different simulations are carried out and the evolutions of crack length and density at the surface and in depth are drawn along with the mean values of the five tests (bold line). These results are presented in Figs. 16-19. The crack length is just the sum of all crack lengths of the network, while the crack length density is the crack length divided by the area of the polygon limiting the network, as presented in Fig. 14. The number of cracks is the total number of independent cracks. Finally, the length of cracks measured in depth is calculated at the end of the simulations, that is to say, when the crack networks are fully developed.

The crack length evolution shows first that the lower the temperature load, the higher the number of cycles to initiation.
Moreover, for each test, after a certain number of cycles, the length evolution sharply slows down. This comes from the fact that the global stress into the sample decreases because large cracks decrease the global stiffness of the sample. Besides, the lower the thermal load, the lower the maximal length, since, as explained before, there is less cracks when the temperature variation is low. It is also interesting to note that some curves (with black arrows on Fig. 16) stop because the maximal number of broken elements (related to the computation time) was reached. This remark is still valid for the following Figs. 17 and 18.

The evolution of the crack length density is in accordance with the remarks done about the length evolution: final density is lower when the temperature variation is smaller. Moreover, at the beginning, initiation is the main reason of the network area growth. Hence, the curve picks of the two lowest temperature loads correspond with the fact that after a few cycles, propagation is prominent in front of initiation.

The number of cracks evolutions (Fig. 18) show that the higher the temperature load, the higher the number of cracks. This comes from the fact that crack initiation is higher for higher temperature loads. Moreover, the decrease of curves at the end corresponds to the stopping of crack initiation and the crack coalescence due to propagation.

The crack length evolutions in depth are in accordance with the fact that, for a higher temperature load (and a constant period of thermal shocks), the number of crack initiation on the surface is higher on the one hand and the stress gradient in depth is also higher on the other hand. Consequently, it is meaningful to see that at the surface of the sample the network grows more for a high temperature load than for a low one, 


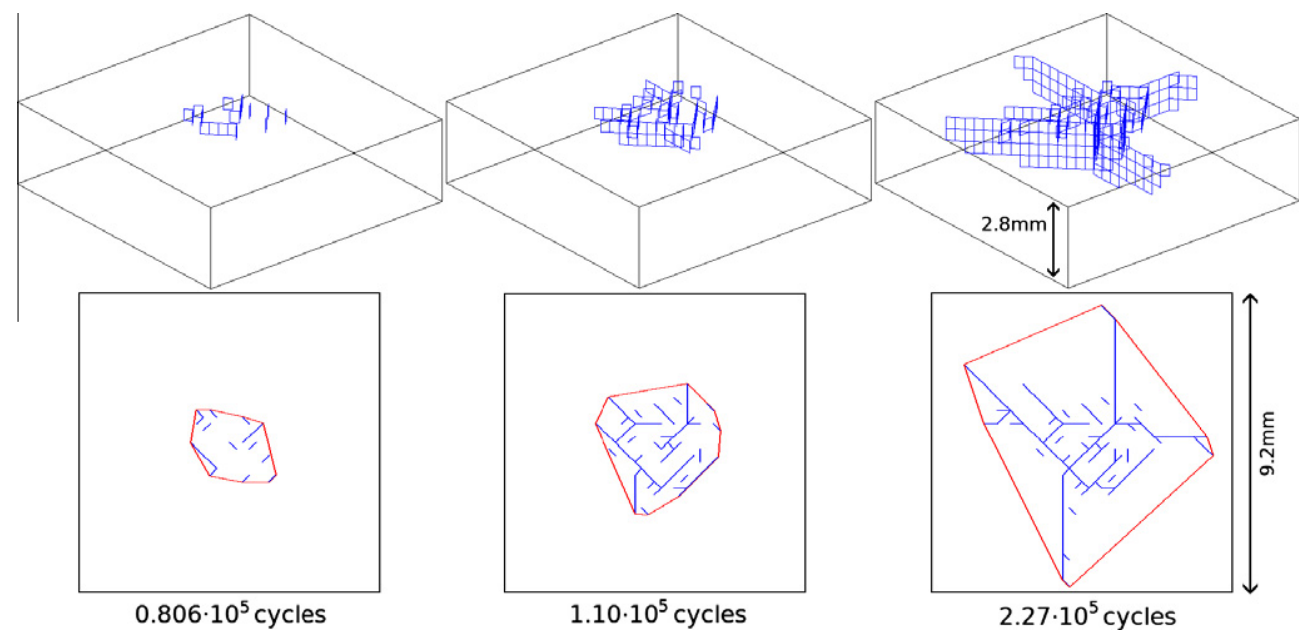

Fig. 14. Crack network evolution for $\Delta T=200^{\circ} \mathrm{C}$ (3D and top views).

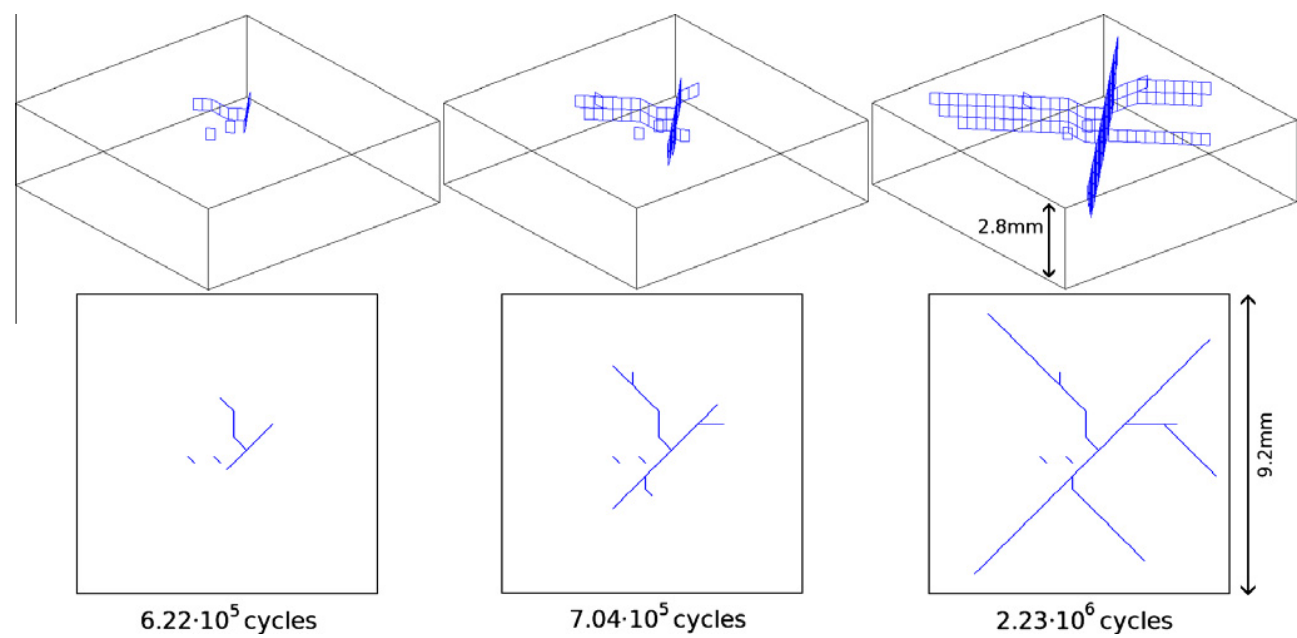

Fig. 15. Crack network evolution for $\Delta T=150{ }^{\circ} \mathrm{C}$ (3D and top views).

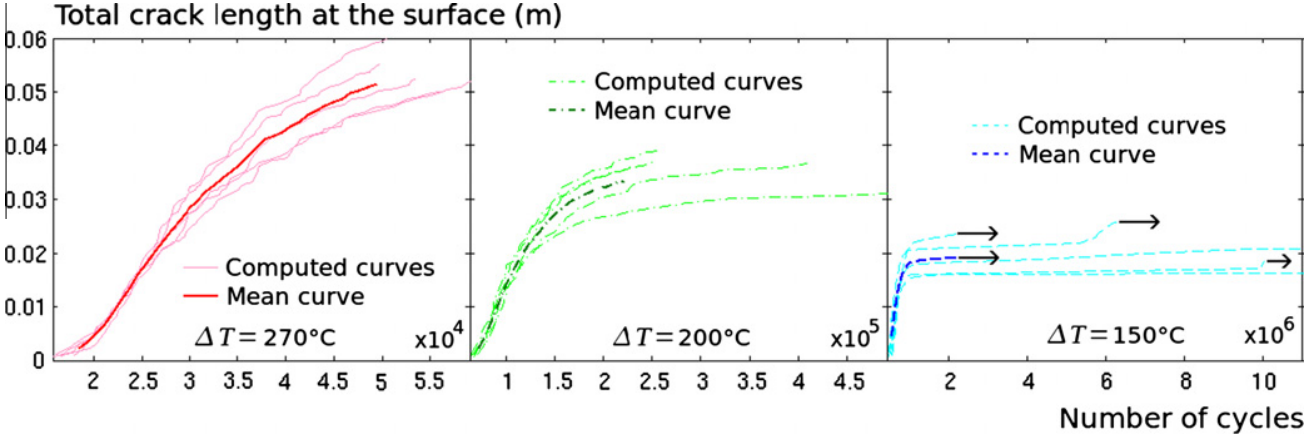

Fig. 16. Computed crack length evolutions (and their mean curves) at the top surface of the sample for $\Delta T$ equals $270{ }^{\circ} \mathrm{C}, 200{ }^{\circ} \mathrm{C}$ and $150{ }^{\circ} \mathrm{C}$.

whereas it is the contrary in depth: it grows more for a low temperature load.

\section{Conclusion}

A new way to model both mechanical and thermo-mechanical crack network fatigue on steel via a FE computation has been presented. This one reproduces the crack network development inside a loaded metal sample while taking into account the stress field evolution: shielding and amplification effects. The model controlling this evolution is based on the distinction between initiation and propagation thanks to both independently fitted laws depending on a FE approximations of the strain field. The three dimensional crack networks develop inside a regular cohesive element mesh by diminishing the stiffness of the broken elements. The model has been tested for one dimensional fatigue simulations showing a good qualitative and quantitative agreement with 
Crack length density evolution at the surface $(1 / \mathrm{m})$

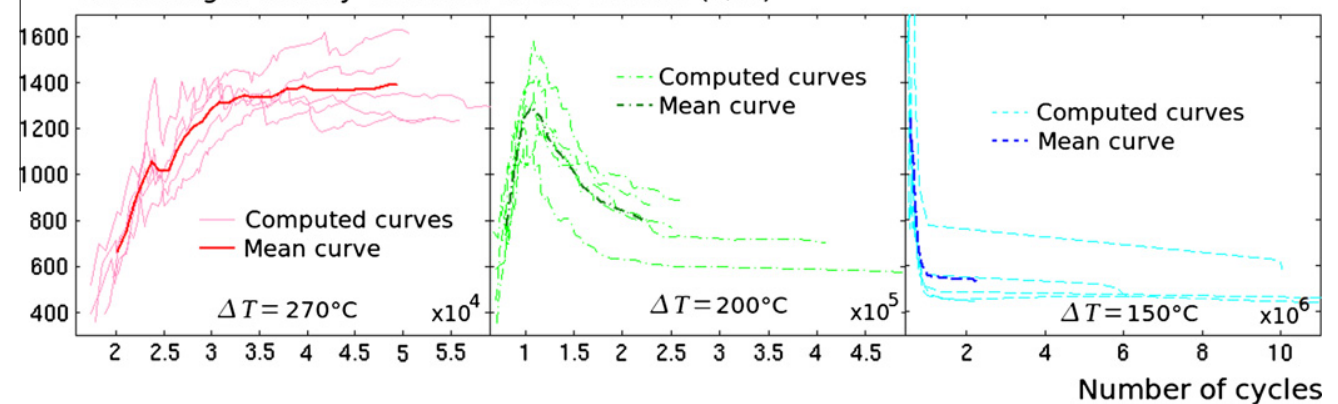

Fig. 17. Computed crack length density evolutions (and their mean curves) at the top surface of the sample. for $\Delta T$ equals $270{ }^{\circ} \mathrm{C}, 200{ }^{\circ} \mathrm{C}$ and $150{ }^{\circ} \mathrm{C}$.

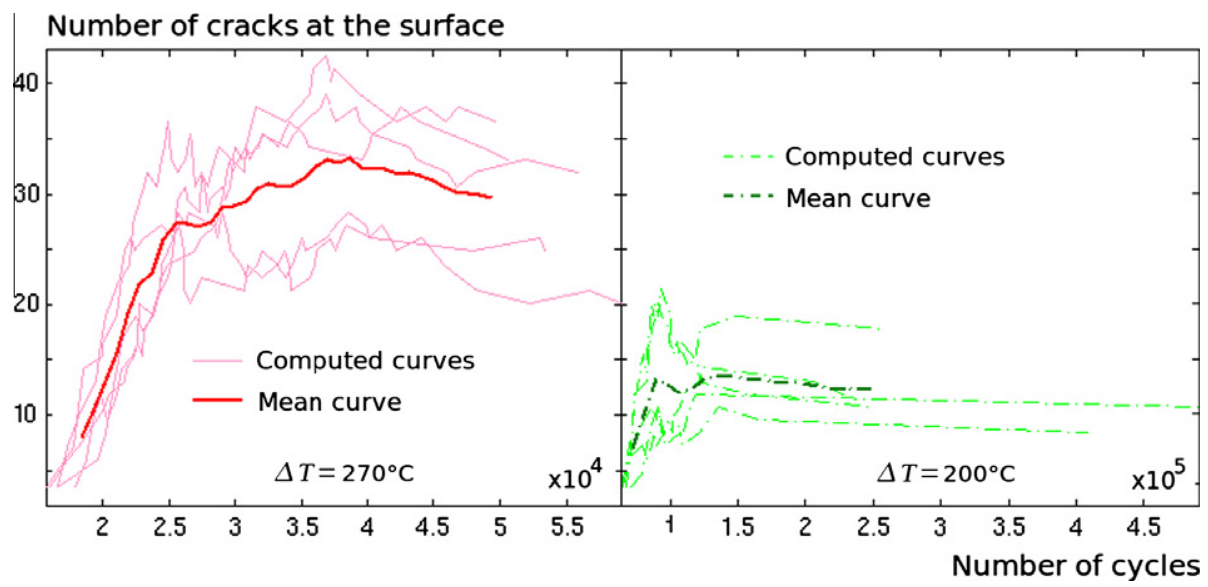

Fig. 18. Computed number of cracks evolutions (and their mean curves) at the top surface of the sample. for $\Delta T$ equals $270{ }^{\circ} \mathrm{C}$, $200{ }^{\circ} \mathrm{C}$.

\section{Total crack length in depth $(\mathrm{m})$}

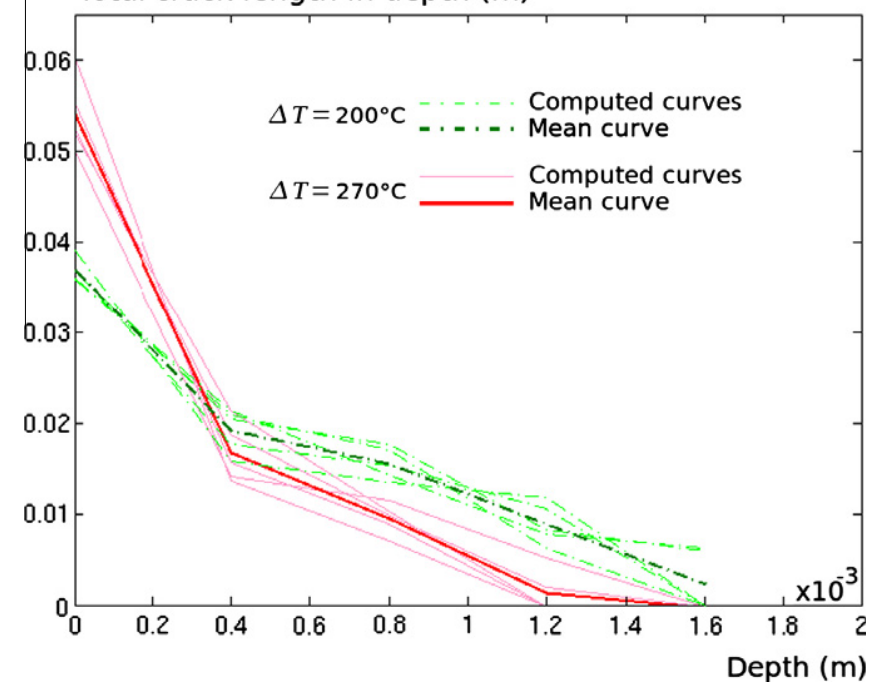

Fig. 19. Computed crack length evolutions (and their mean curves) in depth at the end of the simulation for $\Delta T$ equals $270{ }^{\circ} \mathrm{C}$ and $200{ }^{\circ} \mathrm{C}$.

experimental results. Hence, the accuracy of this agreement makes this model relevant for mechanical fatigue simulations. Similarly, it has been tested in the case of three dimensional thermal fatigue loading representing suitably the effect of repeated thermal shocks onto the crack network development. Besides, since this model is efficient in spite of some rough assumption, it seems interesting to alleviate some of them. First an elasto-plastic law can be introduced into the FE element computation to get a better approximation of the strain field. Then, initiation and propagation laws can be improved taking into account plasticity parameters. A mesh-refinement could also be performed to check mesh sensitivity of the model and to improve it. This will be computationally heavier and needs to fit again initiation law parameters. Finally, richer elements can be used for FE simulation (X-FEM for instance, [27]) to let the crack network designing his own way.

\section{References}

[1] Robert N, Economou J, Cornuel F, Volte O, Stephan J-M. Investigations of mixing zones subject to thermal fatigue. In: International symposium on the contributions of materials investigations to improve the safety and performance of LWRs. Fontevraud, France; 2006.

[2] Faidy C. La fatigue thermique dans les centrales nucléaires: enseignement du retour d'expérience. In: Proc of international conference on the contribution of materials investigations to the resolution of problems encountered in pressurized water reactors. Fontevraud, France; 2002. p. 847-57.

[3] Kamaya M, Taheri S. A study on the evolution of crack networks under thermal fatigue loading. Nucl Eng Des 2008;238:2147-54.

[4] Kane A, Doquet V. Surface crack and cracks networks in biaxial fatigue. Eng Fract Mech 2006;73:233-51.

[5] Maillot V, Fissolo A, Degallaix G, Degallaix S. Thermal fatigue crack networks parameters and stability: an experimental study. Int J Solids Struct 2005;42: 759-69.

[6] Ancelet O, Chapuliot S, Henaff G. Comparative analysis of three thermal fatigue experiments. Fatigue Fract Eng Mater Struct 2008;31:788-802.

[7] Lejeail Y, Kasahara N. Thermal fatigue evaluation of cylinders and plates subjected to fluid temperature fluctuations. Int J Fatigue 2005;27:768-72.

[8] Kawasaki N, Kobayashi S, Hasebe S, Kasahara N. Spectral thermal fatigue tests under frequency controlled fluid temperature variation - transient temperature measurement tests. In: Proceeding of PVP206-ICPVT-11. Vancouver, Canada; 2006.

[9] Curtit F, Stephan J-M. Intherpol thermal fatigue test. In: Proc ASME pressure vessels and piping conference, vol. 3. Denver (USA); 2005. p. 331-7. 
291

[10] Haddar N, Fissolo A. 2D simulation of the initiation and propagation of crack array under thermal fatigue. Nucl Eng Bes 2005;235:945-64.

[11] Haddar N, Fissolo A, Maillot V. Thermal fatigue crack networks: a computational study. Int J Solids Struct 2005;42:771-88.

[12] Yang ZJ, Bu XT, Chen JF, tiu GH. Monte Carlo simulation of complex cohesive fracture in random heterogeneous quasi-brittle materials. Int J Solids Struct 2009;46:3222-34.

[13] Raje N, Slack T, Sadeghi F. A discrete damage mechanics model for high cycle fatigue in polycrystalline materials subject to rolling contact. Int J Fatigue 2009;31:346-60

[14] Rabczuk T, Bordas S, Ri G. On three-dimensional modeling of crack growth using partition of unity methods. Comput Struct 2010;88(23-24):1391-411.

[15] Malésys N, Vincent L, Held F. A probabilistic model to predict the formation and propagation of crack networks in thermal fatigue. Int J Fatigue 2009;31: 565-74.

[16] Rupil J, Held F, Vincent L, Roux S. Identification and probabilistic modeling of mesocrack initiations in 304L stainless steel. J Multiscale Compute Eng 2011;9:445-58.

[17] Palmgren A. Endurance of ball bearings. Z Ver Deut Ing 1923;68:339-41.

[18] Miner MA. Cumulative damage in fatigue. J App Mech - Trans ASME 1945;12:A159-64.

[19] Lawn B. Fracture of brittle solids. Ind ed. Cambridge University press; 1993.

[20] Maillot V. Amorçage et propagation de reseaux de fissures de fatigue thermique dons un acier inoxydable austénitique de type X2 CrNi18-09 (AISI 304L), Ph. D. Thesis (in French), Ecole Centrale de Lille; 2004.
[21] Poncelet M, Barbier G, Rake B, Curtin S, Desmorat R, Le-Roux JC, et al. Biaxial high cycle fatigue of a type $304 \mathrm{~L}$ stainless steel: cyclic strains and crack initiation detection by digital image correlation. European J Mech A/Solids 2010;29:810-25.

[22] Malésys N. Modélisation probabiliste de formation de réseaux de fissures de fatigue thermique, Ph.D. thesis (in French), Ecole Normale Supérieure de Cachan; 2007, <http://hal.archives-ouvertes.fr/>.

[23] Amiable S. Prédiction de durée de vie de structures sous chargement de fatigue thermique, Université de Versailles Saint-Quentin, Versailles; 2006.

[24] Francou L, Chaise S, Vincent L, Hervé P. Mesure par caméra infrarouge du champ de temperature au coors d'un choc thermique. Application à la fatigue thermique d'aciers inoxydables austénitiques, $17^{\text {ème }}$ Congrés Français de Mécanique, Troyes; 2005.

[25] Rupil J, Poncelet M, Rake B, Vincent L, Desmorat R, Le-Roux JC, et al. Essais de fatigue équibiaxiaux à grand hombre de cycles sur un lacier inoxydable austénitique AISI 304L: Utilisation de la corrélation d'images pour mesurer les amplitudes de deformation et détecter les reseaux de fissure. In: Congrès Français de Mécanique, Besançon; 2011.

[26] Fissolo A, Amiable S, Ancelet O, Mermaz F, Stelmaszyk JM, Constantinescu A, et al. Crack initiation under thermal fatigue: an overview of CEA experience. Part I: Thermal fatigue appears to be more damaging than uniaxial isothermal fatigue. Int J Fatigue 2009;31:587-600.

[27] Moës N, Dolbow J, Belytschko T. A finite element method for crack growth without remeshing. Int J Numen Methods Eng 1999;45:601-20. 